\title{
Mycoplasma encephalitis
}

INSERM

\section{Source}

INSERM. (1999). Orphanet: an online rare disease and orphan drug data base.

Mycoplasma encephalitis. ORPHA:83482

Mycoplasma encephalitis is a rare infectious encephalitis characterized by an acute onset of neurological signs and symptoms (e.g. altered consciousness, seizures, headaches, meningeal signs, behavioral changes) due to bacterial infection by Mycoplasma pneumoniae. Patients typically present unspecific signs and symptoms, such as fever, nausea, vomiting, fatigue, prior to onset of neurological manifestations and frequently have a history of a respiratory tract infection (e.g. pneumonia, bronchiolitis, pharyngitis). 